\title{
Una simpatía republicana: Instintos sociales y compromisos políticos
}

\author{
Nicole Darat G.
}

Universidad de Valladolid, Valladolid, España. Email: nicole.darat@alumnos.uva.es

Resumen: El presente texto tiene como objetivo problematizar el proyecto republicano de democracia igualitaria desde la perspectiva de su realizabilidad. Se trata de contraponer el optimismo que encontramos por parte de quienes participan de los movimientos de la sociedad civil, con la perspectiva desencantada o insuficientemente comprometida de algunos sectores de la sociedad, que pese a apoyar las reivindicaciones en cuestión, no están dispuestos a hacer los sacrificios que un compromiso sustantivo demanda. Releer el proyecto republicano desde la simpatía, nos permite comprender los desafíos que un proyecto político republicano debe afrontar para llevar a cabo las transformaciones sociales necesarias. patía.

Palabras clave: Republicanismo, Naturalismo, Movimientos Sociales, Sim-

\section{A republican simpathy: social instincts and political commitments}

\begin{abstract}
The following text's goal is to tackle with the republican project of egalitarian democracy from the point of view of its realizability. The aim is to oppose the optimism that we find in those engaged in civil society movements, to the disillusioned or not sufficiently engaged perspective from certain parts of society, who despite of supporting those claims, are not willing to make the sacrifices that a substantive commitment demands. Re-reading the republican project from sympathy allows us to understand the challenges that a republican political project must face to carry out the social transformations needed.
\end{abstract}

Key words: Republicanism, Naturalism, Social Movements, Sympathy.

\section{A simpatias republicanas: Instintos compromissos sociais e políticos}

Resumo: O presente trabalho tem como objetivo problematizar o projeto republicano de democracia igualitária do ponto de vista de sua capacidade de realização. O proposito é contrastar otimismo encontrado dos participantes de movimentos da sociedade civil, com a perspectiva desencantada ou insuficientemente cometida por alguns setores da sociedade, que apoiando as reivindicações em causa não estão dispostos a fazer o sacrifícios exigir um compromisso substancial. Releiendo o projeto republicano de simpatia, vamos entender os desafios que um projeto político republicano deve cumprir para realizar as mudanças sociais necessárias.

Palavras-chave: republicanismo-Naturalismo-Simpatia-movimentos sociais. 


\section{Introducción}

En los últimos treinta años, pareciera que la denominada filosofía política normativa se hubiera entrampado en una discusión sobre el límite del poder que el gobierno puede ejercer sobre el individuo, a partir del análisis de ciertos conceptos fundamentales como la libertad, la igualdad, la autonomía, la participación política y la justicia, solo por mencionar algunos. Estas discusiones han tenido lugar desde la aglomeración de bandos de defensores y defensoras de posturas distintas, e incluso opuestas, en torno a estos conceptos fundamentales y las consecuencias políticas de los mismos. Es así como la aparición en 1971 de Teoría de la Justicia de John Rawls (Rawls 1979), abrió un debate cuyos ríos de tinta fluyen hasta nuestros días, forzando la discusión en torno a la definición de "libertad", "igualdad” y "justicia”; pero también llevando a sus adversarios y adversarias a pensar en aquellas nociones ignoradas por la teoría, como la participación política, el lugar de la familia en la estructura básica y el papel de la comunidad en la formación de un sentido de la justicia, o la redistribución económica más allá de las fronteras nacionales, Tanto el debate de las definiciones rawlsianas, como la puja por la inclusión de los conceptos excluidos de estas, son los temas que han nutrido a la filosofía política desde entonces.

Los bandos que han aglomerado el trabajo académico de la filosofía política en estos años son principalmente tres: liberalismo, republicanismo y comunitarismo. Existen, por supuesto, infinidad de propuestas que no pueden ser etiquetadas sin más con uno de estos rótulos, como por ejemplo; propuestas que han procurado hacer congeniar liberalismo y republicanismo, como el republicanismo liberal de Robert Dagger; o intentos por conciliar liberalismo y comunitarismo, como lo hace Will Kymlicka; o las propuestas feministas liberales o republicanas. También en los años 70 advino el llamado revival del republicanismo que habría comenzado con la publicación de El Momento Maquiavélico de J. G. A. Pocock en 1975, libro que propusiera una relectura de las tradiciones políticas que habrían influenciado el pensamiento de los independentistas norteamericanos. El republicanismo se convirtió entonces en el principal adversario teórico del liberalismo político rawlsiano, centrando la discusión en la ambigua posición de aquel frente a la participación en el espacio público y sobre la legitimidad de la promoción de la virtud cívica.

El debate en la filosofía política actual, principalmente en la academia anglosajona, habría que precisar, sigue caminando por esta senda, aunque los énfasis han ido variando con el tiempo y discusiones que prevalecieron durante los años 90 como el lugar de la virtud cívica en el liberalismo, frente a la teoría política republicana, ha ido dando paso a la discusión en torno a la ciudadanía, el cuestionamiento de la economía de mercado y la justicia global. Temas que con la actual crisis económica que azota Europa adquieren creciente preponderancia en los espacios de debate académicos que se cuestionan sus propias condiciones de existencia. 
La coyuntura política y social en Chile hoy, pone sobre la mesa una serie de temas que reclaman ser discutidos por la sociedad civil y por las distintas instancias del poder político y que la academia ha intentando abordar durante el último año. No solo se trata de una discusión sobre la necesidad de una educación gratuita de calidad, sino de la puesta en evidencia del desgaste de las instituciones políticas y económicas heredadas de la dictadura, que han impedido el desarrollo igualitario que el regreso a la democracia prometía, la más fundamental: la exigencia de una asamblea constituyente que redacte una nueva constitución. Frente a este escenario de exaltación social, tanto nacional como internacional, que reclama para sí lo político(Rancie_re 2006), la retórica republicana parece ser el lenguaje más apropiado para la filosofía política hoy; no obstante entre el optimismo de lo político y la realidad de lo social, habría un hiato que es preciso poner de manifiesto.

Si, tal como afirma Habermas, la tarea de la filosofía política es aclarar los conceptos que están presentes en las prácticas políticas y sociales, entonces he aquí una tarea de la que debemos hacernos cargo. ¿En qué consiste este hiato entre los discursos de transformación de lo político y las resistencias de lo social? ¿Existe realmente este hiato? Responder a esta pregunta implica hacer explícitos los supuestos que operan en el diseño de nuestras instituciones y que son los supuestos de la teoría económica y política que conforman el tejido del ethos de las sociedades liberales en general y de la chilena en particular.

Son estos supuestos que operan al nivel de la cotidianeidad los que constituyen las mayores resistencias de la sociedad a las transformaciones políticas profundas, supuestos que provienen principalmente de las ciencias sociales y biológicas en torno a la naturaleza humana y que apuntan a describir las motivaciones que subyacen a nuestras interacciones sociales.

De entre estos supuestos, uno de los que mayor influencia ha tenido en la filosofía política contemporánea ha sido el de la "reciprocidad autointeresada”, frente al altruismo y la solidaridad. Es precisamente la idea de que uno cooperará si los demás también cooperan (reciprocidad), la que se encuentra a la base de un planteamiento como el expuesto por Rawls en Teoría de la Justicia, así como en sus trabajos posteriores. Este supuesto que ha sido el credo de la economía y de las llamadas behavioral sciences, ha sido asumido demasiado pronto por la ética y la filosofía política, que han renunciado a pensar las motivaciones ciudadanas más allá de la reducción final de toda acción a un interés egoísta ulterior. Reproduciendo ambas el sentido común de la sociedad, sancionan dicho supuesto como la columna vertebral de una antropología realista. En este contexto, las reivindicaciones sociales y políticas que exigen una transformación profunda de la sociedad, no pueden sino ser vistas con recelo por una sociedad donde las prácticas ciudadanas se ven con temor y la estrategia más provechosa sigue siendo la del homo oeconomicus.

Explorar estos supuestos nos permite evidenciar esa distancia entre 
una aceptación de las reivindicaciones de los movimientos sociales, y un deseo efectivo de vivir de acuerdo a los principios de una sociedad igualitaria. En este artículo pretendo defender que el homo oeconomicus no es más que una construcción falaz de la naturaleza humana, que toma la parte por el todo, considerando una fuente motivacional, el egoísmo, que no es más que una fracción de la naturaleza humana, como si se tratase de un impulso omnipresente.

Aquí intentaremos mostrar cómo los supuestos antropológicos y psicológicos presentes en la mayoría de los proyectos políticos liberales, se basan en una asunción acrítica del egoísmo, que hace improbable el éxito de un proyecto basado en acciones que no redundan finalmente en beneficios para el individuo, como lo son la solidaridad y el compromiso cívico, tal como lo supone el republicanismo. Y son precisamente este tipo de supuestos, más o menos explicitados, los que nos permiten distinguir finalmente una postura liberal de una republicana o radical. Con todo, pareciera que las mismas corrientes republicanas actuales han asumido que la participación política es un medio para la consecución de un bien ulterior: la libertad y no ya un modelo completo de vida buena. El problema con esta concepción instrumental de la virtud cívica, es que no logra explicar cómo la participación política efectivamente existente, tiene lugar, y tampoco logra justificarla en un plano normativo, es decir, si la participación es un mero medio para conseguir un fin, ¿por qué no buscar otro medio más eficiente y menos demandante para producir dicho fin? Esto último es particularmente nocivo para una teoría republicana, pues la participación en lo público es uno de sus rasgos distintivos y un elemento constitutivo del concepto republicano de libertad. De acuerdo con Félix Ovejero y Roberto Gargarella

"El republicanismo insiste en que ningún diseño institucional es completo y, en tal sentido, adecuado, si se desentiende del tipo de ciudadanos necesarios para que dicho diseño pueda mantenerse en pie. Toda negligencia respecto de este vínculo ciudadanos-instituciones acabará por provocar el socavamiento del esquema político sin importar lo sofisticado que sea el mismo.” (Gargarella, Martí, y Ovejero 2003: 38)

No desentenderse del tipo de ciudadanos (y ciudadanas habría que agregar) que se necesitan para llevar a cabo una transformación profunda de la sociedad, implica atender a las concepciones de la naturaleza humana que subyacen a los proyectos políticos. De la falta de atención solo pueden resultar proyectos que piden muy poco, asumiendo siempre el mínimo de compromiso cívico y que por ende, hacen recaer la estabilidad de las instituciones y la provisión de los bienes públicos fundamentalmente en la coerción. Ese descuido también se aprecia en proyectos políticos que exigen demasiados, o demasiado pronto, sacrificios por parte de sus ciudadanos y ciudadanas para asegurar la estabilidad de un modelo radicalmente igualitario, y que, finalmente acaban apoyándose de forma creciente en la coerción para garantizar la estabilidad y seguridad de la sociedad, o bien, resul- 
tan siendo son atacados violentamente por grupos opositores que ven amenazados sus intereses, como ha sido el caso de Chile y España, donde los proyectos republicanos fueron abruptamente interrumpidos por las armas.

Frente a este panorama ¿Qué podemos efectivamente esperar de los ciudadanos y ciudadanas, con vistas a la construcción de un proyecto republicano? ¿Es insalvable el hiato entre la expectativa de una sociedad igualitaria, y los ciudadanos y ciudadanas reales, que finalmente habrán de vivir en ella? En lo que sigue, intentaré responder estas preguntas, sirviéndome de un marco teórico que generalmente subyace, pero pocas veces se hace explícito en la filosofía política, me refiero al enfoque naturalista de la naturaleza humana, y su estudio por parte de la biología y la economía. Un enfoque naturalista a la vez que crítico, nos permitirá disputar el lugar privilegiado de la antropología liberal del homo oeconomicus.

\section{Más allá del homo oeconomicus. Una antropología política naturalista}

En El origen de las especies de Charles Darwin (2008), el concepto de "bien" aparece vinculado a la noción de selección natural la que, a diferencia de la artificial, es entendida como orientada hacia "el bien del individuo" y no al capricho particular del productor que selecciona las características que más le complacen. Comparando la selección natural con la selección artificial, Darwin dirá:

“Así como el hombre puede producir y ciertamente ha producido un gran resultado mediante los medios de selección metódicos e inconscientes, ¿qué no podría llevar a cabo la naturaleza? El hombre solo puede actuar sobre los caracteres externos y visibles: a la Naturaleza no le interesan para nada las apariencias, excepto en cuanto ellas puedan ser útiles para cualquier ser. Ella puede actuar sobre cada órgano interno, sobre cada sombra de diferencia constitutiva, sobre todo el mecanismo de la vida. El hombre selecciona solo por su propio bien; la Naturaleza solo por aquel del ser que se ocupa. Cada característica seleccionada es puesta plenamente en ejercicio por ella y el ser es puesto bajo condiciones adecuadas de vida." (Darwin 2008: 65)

La selección natural actúa sobre un espacio mucho más amplio que su equivalente artificial, escruta cada parte de los individuos orgánicos, no solo sus características visibles. Si bien su acción es más lenta, sus efectos son más profundos y durables de lo que podrían ser los de la selección artificial. Se nos revela a través de su ironía, el ciego proceso de selección natural tiene una visión más profunda dentro de la naturaleza: ve mejor porque no ve nada, actúa a largo plazo porque no tiene ningún plan y está orientada a la producción del bien porque no sigue ningún plan. La selección natural, así descrita, guarda ciertas similitudes con la noción Smithiana 
de "mano invisible", y podemos notarlo en la superior capacidad de "escrutinio" que Darwin le reconoce, esa capacidad de visión de conjunto, si se quiere, tanto espacial como temporal. La Naturaleza, sin las limitaciones cognitivas a las que está sujeta la mente humana, tiene una mayor capacidad de aprehender cada detalle de una miríada de hechos que se acumulan en el tiempo.

Así como en Darwin podemos encontrar señales de la apelación a un "mecanismo de mano invisible" representado por la selección natural, de igual modo podemos encontrar en Smith un enfoque claramente naturalista, no solo en su conocida frase de la Riqueza de las Naciones, donde afirma que el origen de la división del trabajo no se encuentra en ninguna sabiduría humana sino que es la necesaria aunque lenta y gradual consecuencia de la propensión en la naturaleza humana de intercambiar una cosa por otra. El enfoque naturalista puede advertirse sobre todo, en la descripción que Smith hace de los instintos humanos en su Teoría de los Sentimientos Morales. Habría ciertos instintos básicos que impulsan a los animales y humanos, inconscientemente hacia los fines deseados por la Naturaleza. Esto calza perfectamente con la idea estoica de Naturaleza que opera en el concepto de Smith, una Naturaleza que guía a los que se dejan guiar y arrastra a los que no. La naturaleza asegura el cumplimiento de sus designios (de sus designios ciegos habría que añadir) sirviéndose de estos impulsos. Lo que se busca, tanto en el esquema de Darwin como la idea que sostiene la exposición smithiana, es la autopreservación, lo que se logra junto con la autopreservación es un resultado adicional no intencionado: el bien de la especie o la prosperidad de la sociedad comercial, para Smith.

Es curioso como ambos autores rehúyen hablar de felicidad en primer término, aunque Darwin diga que finalmente los más fuertes y felices son los que sobreviven y Smith, en un tono más sombrío, afirme que en todo el ajetreo de la sociedad comercial difícilmente se encuentra la verdadera felicidad, situando a esta más allá de los intercambios corrientes, en un retiro del sabio, mostrando así el lado más estoico del escocés. La tarea que opera la naturaleza no es la de la felicidad de los individuos vivientes, sino la de su (de la naturaleza) propia perpetuación. La selección natural al igual que la mano invisible, en tanto que procesos ciegos, cuentan con una materia prima común: nuestros instintos e impulsos, el más básico de ellos, la preservación. La selección natural aparece como una fuerza que opera únicamente al nivel del individuo, es decir, el individuo que sobrevive es aquel que posee las características que lo adaptan mejor al ambiente en que vive.

Sin embargo esta idea se matiza en El origen del hombre, cuando no solo refiriéndose a los seres humanos, Darwin haga referencia a la selección natural actuando más allá del nivel del individuo, precisamente para explicar el surgimiento de las cualidades morales, cualidades que por cierto, no considera exclusivas de los seres humanos. Respecto a ellas dirá:

"Su fundamento recae en los instintos sociales, incluyendo en este término los lazos familiares. Estos instintos son de una naturaleza 
altamente complicada, y en el caso de los animales inferiores otorgan tendencias especiales hacia ciertas acciones definidas; pero los elementos más importantes son el amor y la emoción distinta de la simpatía. Los animales dotados de instintos sociales obtienen placer en la compañía mutua advierten del peligro se defienden y se ayudan en muchas otras formas. Estos instintos no se extienden hacia todos los individuos de la especie sino a los de la comunidad. En tanto son altamente beneficiosos para la especie, han sido adquiridos con toda probabilidad, a través de la selección natural.” (Darwin 1981: 391)

Nuestros instintos sociales, producidos por la selección natural para el bien de la especie y para el del individuo que los posee, nos orientan hacia los otros, nos sacan de nuestra finalidad balística de autoconservación y nos hacen cooperar con quienes nos rodean, con los miembros de una misma comunidad o grupo para conseguir un conjunto de bienes que serían imposibles en soledad. Entre los instintos específicos que poseen los animales, nos encontramos con la llamada de aviso de las aves y otros animales sociales que ponen en riesgo su vida al señalarse a sí mismos al depredador y retardar su huída. ¿Cómo podría la selección natural elegir un instinto que pusiera en riesgo a su portador? Este instinto, si bien pone en riesgo a quien lo posee, permite que su grupo viva mucho mejor, que crezca y que sea menos vulnerable a los ataques de los depredadores. Esta mejora en la vida del grupo beneficia tanto a los individuos que se relacionan genéticamente con el ave que da el aviso, como a los que no. En el caso de los humanos, continúa Darwin, que no tenemos instintos específicos, son el amor y la simpatía los que operan cuando nos disponemos a ayudar a los miembros de nuestro grupo. Es en este contexto que Darwin introduce un concepto particularmente enriquecedor para una mirada republicana de la política, el de bien general. ${ }^{1}$

"El bien general puede ser definido como los medios mediante los cuales el mayor número posible de individuos pueden ser criados en pleno vigor y salud, con todas sus facultades perfectas, bajo las condiciones a las cuales están expuestos. Como los instintos sociales tanto del hombre como de los animales inferiores han sido indudablemente desarrollados bajo los mismos pasos, sería recomendable, si fuera practicable, usar la misma definición en ambos casos, y tomarla como el test de la moralidad, el bien general o bienestar de la comunidad, en lugar de la felicidad general, pero esta definición tal vez requiere de cierta limitación en cuanto a la ética política." (Darwin 1981: 98)

Llama la atención que Darwin defina el bien general en términos de "test de moralidad”, es decir, aquellos medios que promuevan el bien general se corresponden con lo moralmente correcto, mientras que aquellos que se le oponen, o lo obstaculizan, serán lo contrario. Darwin se aventura aquí a dar una visión sustantiva del bien: crecer en pleno vigor y salud, con todas sus facultades perfectas. ¿Qué significa esto? Para empezar, el bien 
general son los medios que hacen posible el florecimiento del mayor número posible. Cuáles sean estos medios es algo que Darwin no especifica, pero que parece ser respondido por el contexto general en que este párrafo está inserto: el de los instintos sociales. Detengámonos no obstante en la cuestión del mayor número posible. Creo que nuestra atención no debería centrarse en lo del mayor número, ya que la oposición de Darwin a los principios utilitaristas es de clara oposición, sino en lo de posible. ¿Qué constituye esta posibilidad? Darwin dice "bajo los medios a los cuales están expuestos". No se trata simplemente de una media aritmética, sino de una cuidada atención de las condiciones de la existencia, condiciones que son también tecnológicas (en sentido amplio) para los seres humanos ${ }^{2}$.Si una acción ha de ser considerada como moralmente correcta o buena, debe estar orientada a producir los medios para que la mayor cantidad posible de individuos florezcan. Una acción que teniendo a su disposición los medios para hacerlo, falla en producir este bien, falla en proteger y ayudar a los otros miembros de la comunidad, y permitirles desarrollarse saludables y vigorosos y vigorosas y en darles la posibilidad de desarrollar sus facultades en plena perfección, no es una acción moralmente buena. Esto implica el que el bien general sea un test de moralidad.

Los seres humanos carecemos de instintos especiales, no hay un instinto para proteger la educación y la sanidad pública, por así decirlo, lo que tenemos son los instintos sociales de la simpatía y el amor, que han sido producidos por la selección natural, precisamente porque permitían que las comunidades dotadas de más miembros con estos instintos, florecieran y crecieran más rápido que otras. La definición de bien general aquí dada, se asemeja a aquella de la selección natural en El origen, donde es la naturaleza la que selecciona aquellas características que harán posible que un individuo florezca de acuerdo a las condiciones orgánicas e inorgánicas de su existencia.

Este bien es moral en tanto que es el fruto de los instintos sociales que han sido seleccionados, es decir, en el sentido en que "el mayor número posible” requiere de la actuación de aquellas características que favorecen la cooperación entre miembros de la misma y de distinta especie, como en el caso del acicalamiento, pues si este hábito no hubiese sido seleccionado, la especie se mermaría... menos individuos sobrevivirían. La evolución no es moral ella misma, pero produce la moralidad, a través de los ínfimos pasos que van dando origen a las especies. Y el bien general es un criterio de moralidad, una especie de imperativo categórico naturalista, donde lo que es moral no es lo correcto en sentido formal, sino lo que produce el bien sustantivo, aquello orientado a permitir que más individuos se desarrollen y florezcan.

Si dirigimos nuestra lectura hacia la luz que arrojan las palabras de Smith, encontramos que este era bastante receloso de aquellas acciones que se declaraban como orientadas hacia el bien común. Para Smith, cuando una acción se ponía a sí misma esta etiqueta, siempre solía esconder algún fin mezquino, es por ello que la espontánea coordinación del esfuer- 
zo individual, le parecía un mucho mejor candidato para producir la prosperidad de la sociedad y el florecimiento de sus miembros. La simpatía, invocada en el espacio del mercado no podía sino tener efectos nocivos, a saber, la colusión, por lo que era mejor apelar al amor propio del tendero, que a su compasión si lo que queremos es poner comida en nuestros platos. Pese el énfasis en el propio interés que Smith pone en el centro de su teoría, tanto económica como moral -que es precisamente por lo que suele citarse a Smith- Darwin no lo considerará como uno más de los apologetas del egoísmo, y en cambio basará su definición de la simpatía, principalmente la teoría moral del profesor escocés. Rescatar el camino que sigue Darwin para explicar el surgimiento de los instintos sociales, implica también rescatar una lectura de Adam Smith que suele dejarse de lado, la del Smith de la Teoría de los Sentimientos Morales.

Darwin, no obstante, no desconoce la concurrencia de múltiples motivos en la acción humana, no sin un dejo de desazón reconocerá que el egoísmo muchas veces concurre entre ellos. Es parte de la concepción smithiana de simpatía, la necesidad de generar ese sentimiento en los otros, de ser amados y reconocidas. Esta impureza de los motivos es lo que caracteriza a la acción humana y son estas las motivaciones que se hallarán a la base de la explicación darwiniana de la cooperación, característica fundamental de los animales dotados de instintos sociales. Para Darwin la cooperación se explicaba tanto desde el deseo de recibir algo en retorno como desde la simpatía misma. Sin embargo el rol de la simpatía e incluso el de la confianza, parecen desaparecer en las investigaciones contemporáneas sobre la cooperación basadas en la teoría del altruismo recíproco y que tanta influencia han tenido en la teoría política y en el diseño institucional.

Los instintos sociales nos compelen a cooperar con otros, aun cuando esto afecte nuestra adaptabilidad, nuestras chances de sobrevivir y reproducirnos básicamente; sin embargo esta tensión ha sido reducida por los teóricos del altruismo recíproco: todo acaba siendo reductible al interés personal o, metafóricamente, al de los propios genes. Podríamos decir que esta exclamación es exagerada y que en realidad no hay nada de lo que preocuparse, dado que estas afirmaciones tienen un carácter empírico descriptivo y no normativo, no obstante cuando son tomadas como un datum por la economía neoclásica para explicar la conducta humana, nos encontramos en un plano de lleno normativo, donde la racionalidad misma se define a partir de decidir de acuerdo a una matriz de costos y beneficios, donde cualquier decisión que no incremente de alguna forma el bienestar material del individuo, se considera irracional. Es en este sentido que en el denominado "dilema del prisionero" 3 , la mutua deserción, es decir, el engaño mutuo para obtener el mayor beneficio individual, es la estrategia dominante: la única estrategia que cada individuo puede adoptar considerando su propio bienestar aisladamente.

Sin embargo en los sucesivos experimentos que se han conducido para poner a prueba el comportamiento de los sujetos reales frente a la elección de cooperar y compartir los beneficios y cargas que puede aca- 
rrear una decisión, asimismo como en la vida cotidiana, la deserción ocurre, pero no tan a menudo como debería suceder de acuerdo con los supuestos descriptivos (pero que son también normativos) de la teoría. ¿Por qué ocurre esto? ¿Por qué decidimos cooperar y abandonamos el beneficio potencial de un determinado curso de acción, para elegir otro? La llamada “teoría de la elección racional” no logra capturar la motivación tras acciones cotidianas como ayudar a extraños o involucrarse en política. Podemos preguntarnos entonces: Si nuestra naturaleza como seres sociales, involucra un entramado motivacional complejo, capaz de albergar la simpatía y el altruismo, a la vez que el egoísmo y la crueldad ¿Es real este hiato al que nos hemos referido, o es simplemente un reflejo de la pluralidad de nuestras motivaciones, de nuestra naturaleza caída como solían llamarla los pensadores cristianos?

\section{Hacia una política de la simpatía}

La cooperación social es fundamental para resolver problemas políticos básicos, como la provisión de bienes públicos, tales como el respeto de las leyes e instituciones, desde el respeto de las normas del tránsito, hasta el pago de los impuestos, además de la participación política que hace posible la elección de representantes y que abre canales de participación alternativos a la política representativa tradicional, hoy en crisis.

La explicación preferida de los teóricos y teóricas liberales para fundamentar el funcionamiento de una sociedad democrática, ha sido la de la reciprocidad: un individuo coopera si tiene la certeza de que los demás también cooperarán. Esta asunción, aunque en apariencia evidente, genera numerosos problemas, entre ellos el de la dificultad de proveer dicha certeza en sociedades amplias que se caracterizan por el anonimato, además de la cuestión de qué sucede con los miembros no cooperativos de la sociedad. ¿Qué fundamento encuentra aquí el que nos ocupemos de los ancianos y ancianas, de quienes tienen niveles importantes de discapacidad mental o física y no pueden o no pueden ya reciprocarnos? Afirmar que estamos invirtiendo en compasión, a la espera de inspirar compasión en otros que observan, parece no capturar la complejidad de la cuestión, por decirlo de algún modo. La idea de que somos animales dependientes, refuerza la idea de que necesitamos de los demás para desarrollarnos en la plenitud de nuestras capacidades, y debilita la apuesta por una moral en que la fase más alta del desarrollo sea el punto en que somos completamente independientes de los demás. Es esta dependencia, propia de animales con cerebros tan grandes y, por ende, con una etapa de niñez tan prolongada, la que explica la evolución de nuestros instintos sociales. A propósito de esto resulta interesante revisar la posición del filósofo de la biología, Michael Ruse:

“La moralidad ha sido puesta ahí por la selección natural en orden a hacer que trabajemos juntos socialmente o que cooperemos (...) Esto no quiere decir que siempre cooperemos o seamos morales. Somos influenciados por muchos factores, incluyendo deseos egoístas y de 
otro tipo. Pero la moralidad es uno de esos factores, y en suma los humanos generalmente trabajamos juntos. A veces la moralidad resulta contraproducente. Puedo ir en ayuda de un niño ahogándose, y ahogarme yo mismo. Esto va difícilmente en mi auto-interés. Pero en balance, va en mi propio interés ayudar a gente en apuros, principalmente a niños en apuros.” (Ruse 2009:20)

Es interesante analizar la postura de Ruse a este respecto, el autor parte de la idea de que la moralidad es una adaptación destinada a producir la cooperación entre animales particularmente dependientes como lo somos los seres humanos, pero en la medida en que se trata de una adaptación, Ruse procura explicarla en términos de su utilidad para el individuo: aunque la moral pueda ser contraproducente a veces, en general produce ventajas adaptativas para nuestra especie, nos hace más aptas y aptos para hacer frente a las presiones de nuestro medioambiente. Una acción motivada moralmente, orientada a la producción del bien general habría que decir con Darwin, acaba siempre procurándonos algún beneficio, sino a nosotros mismos, tal vez a nuestra descendencia, y es por esto que, tal como Ruse lo entiende, siempre hay una reciprocación de la acción altruista. Esto explica por qué la moralidad ha sido "puesta ahí" por la selección natural, explica la utilidad de unos instintos sociales que a veces pueden llevarnos a poner en riesgo nuestra propia vida: tienen un potencial beneficio para el individuo, pero también, aunque Ruse no lo diga, tienen un beneficio potencial para el grupo al que el individuo pertenece.

Con todo, quienes se apoyan en la teoría del altruismo recíproco para explicar la cooperación social, que constituyen la mayoría de los estudiosos y estudiosas, desde los años 70 hasta ahora, toman como base, la teoría de Robert Trivers, principalmente lo expuesto en su artículo de 1971, The evolution of reciprocal altruism. En este artículo, Trivers expone un ejemplo particularmente interesante:

"Un ser humano que salva a otro con quien no está relacionado y que está a punto de ahogarse, realiza un acto de altruismo. Asumamos que la chance de que el hombre que se está ahogando, muera, es del $50 \%$ si nadie se lanza a rescatarlo, pero la chance de que quien lo salve, se ahogue, es mucho más pequeña, digamos, una en 20. Asumamos que el hombre siempre se ahoga si quien lo salva se ahoga y que se salva si su rescatador se salva. También asumamos que el gasto energético de quien salva es trivial en comparación con las probabilidades de supervivencia. Si fuera un hecho aislado el rescatador o rescatadora no se molestaría en salvar al hombre que se ahoga”. (Trivers 1971: 35, 36)

Bien, hasta aquí el ejemplo que leído con intención, tiene demasiadas asunciones, tantas que lo hacen irreal. Sin embargo se trata de un modelo: estas son las condiciones que deben darse para que una acción aparentemente desinteresada se explique a través del altruismo recíproco. Bien. Pero ¿se cumplen estas condiciones en los intercambios en la vida real? Al 
parecer todas las condiciones son las exigencias típicas de un modelo, salvo la última y que es finalmente la más prescriptiva: "si este fuera un evento aislado el rescatador o rescatadora no se molestaría en salvar al hombre que se ahoga.” El sujeto de Trivers parece estar completamente desprovisto de simpatía, pues esta no ha jugado ningún papel en su decisión de rescatar al hombre. Se trata de una mente calculadora que trabaja bastante rápido, que es capaz, no solo de evaluar las posibilidades de éxito del rescate y la relación costos beneficios entre su energía y el incremento de las posibilidades de sobrevivir del hombre ahogándose, esto después de todo podría hacerlo alguien que nade a menudo y que tenga conocimiento de sus capacidades, alguien así podría hacerlo instantáneamente. Lo que no puede hacer instantáneamente y tal vez tampoco tras una deliberación razonable (que a medida que avanza va modificando los valores de supervivencia), es saber que habrá una segunda oportunidad en que su acción pueda ser reciprocada y es esta la condición necesaria, aunque no per se suficiente, para que se decida finalmente a actuar. Sin esa certeza, no habría rescate y es precisamente esta certeza la que no es lícito suponer.

Las explicaciones del altruismo recíproco de Trivers, sobre las que más tarde abundaría Axelrod (1984) y popularizaría Dawkins (2006), se basan en unas condiciones en que la iteración puede ser dada por sentada y sin embargo, nuestra vida cotidiana no es así, no solo por la presión existencial de nuestra finitud, sino porque nunca sabemos, sobre todo si se trata de un extraño en condiciones extremas, si acaso ha considerado el acto como un juego de una sola partida. Deberíamos tal vez dudar si su agradecimiento es muy emotivo, pues si habrá reciprocación, se trata principalmente de un contrato tácito. La verdad es que tal vez nunca vayamos a ver a ese extraño y entonces habremos perdido energía en vano.

De acuerdo con Darwin en los seres humanos conviven los sentimientos de simpatía y el egoísmo, ambas motivaciones se mezclan en la acción. Tal vez las motivaciones egoístas se vean defraudadas si nunca podemos obtener un favor semejante a cambio de nuestra valentía.

Sin embargo aún hay explicaciones que, sin renunciar a la tesis del egoísmo, podrían dar cuenta del arrojo de nuestro héroe o heroína de mente calculadora: el intento de construir una reputación. Esta motivación es fácilmente comprensible desde el marco de la teoría de los sentimientos morales de Smith: queremos ser amados y amadas y tener una reputación de ser personas heroicas, ciertamente sirve a esa función. Nos hace parejas altamente atractivas, excelentes socios o socias comerciales. Una persona capaz de salvar a un extraño de forma desinteresada, nos da las señales que buscamos para confiar plenamente en alguien. El cine de Hollywood está lleno de estas imágenes, el protagonista, en general un varón, hace algún tipo de acto heroico o tremendamente dadivoso, altruista como sea, con mayor o menor suerte para volverse atractivo a los ojos de una chica que en condiciones normales no lo encontraría atractivo. Esta confianza ganada por medio de la reputación puede o no ser traicionada, puede ser ganada con la finalidad exclusiva de traicionarla o puede ser traicionada por error 
o torpeza. Pero cuando una acción se ejecuta desde la sola motivación de producir una reputación, es probable que esta reputación sea falsada si las circunstancias cambian, por cualesquiera razones.

¿Por qué una reputación ganada en torno a la falsedad o a aquello que Smith llamaba vanidad -ese deseo de ser amado no por las razones correctas, y que se opone a la virtud- es más frágil que una reputación formada desde sentimientos genuinos? Podemos señalar dos razones para ello, una reside en el agente y la otra en el receptor de esa información que la reputación provee. Si un individuo actúa de una manera aparentemente irracional, es decir, aparentemente arriesgando su vida para salvar a otro, o incluso para castigar una violación a las normas sociales, pero lo hace finalmente desde una "mente calculadora” para usar las palabras del propio Trivers, fácilmente el beneficio económico, que es su motivación última puede encontrarse en la acción opuesta, si las condiciones cambian. Puedes buscar la amistad o el amor de alguien por su buena fortuna y dar a cambio tu amor, tu compañía y tu ayuda, produciendo un beneficio para ambas partes, pero si tu motivación es la buena fortuna y no el amor de la otra parte, si esa fortuna se acaba, es racional pensar que tu amor también lo hará. El amor incondicional es en este sentido, irracional.

Si la disposición genuina no subyace la acción aparentemente altruista, dadas las cambiantes circunstancias a las que podemos someternos y principalmente las tentaciones de beneficios a corto plazo que puede ofrecer traicionar la confianza de quienes creen en nosotros, la ausencia de una disposición genuina, o la merma de ella, puede fácilmente acabar en la jugada de la "tentación” en el dilema del prisionero, obteniendo los máximos beneficios de la cándida jugada de nuestra contraparte, a no ser que esta tenga motivos para sospechar y su jugada sea también la deserción, en cuyo caso ambas partes perdemos, o bien puede que nuestra contraparte elija castigarnos, no volviendo a cooperar. La selección natural así como favorece el engaño, favorece las habilidades para detectar potenciales tramposos. Estas son ideas propias de Trivers y que, sin embargo, no suelen considerarse en las discusiones en torno a su trabajo y al concepto de altruismo recíproco que éste ha contribuido a popularizar. Aún dentro del marco ético predominante en la actualidad que constituye el altruismo recíproco, la acción aparentemente altruista, esa que se hace en la espera de una contraprestación, si carece de las emociones que la fundamentan, no puede mantenerse con seguridad en el tiempo. La cooperación cínica acaba siendo un despropósito, pues no puede conseguir a largo plazo los beneficios que espera obtener mediante su interesado gesto.

La idea de la cooperación interesada, que es la del altruismo recíproco, anida en lo profundo del sentido común de la sociedad, y es así como es difícil lograr la cooperación y el compromiso en una acción que no parece rendir frutos inmediatos o directamente beneficiosos para los actores implicados. Cada quien quiere saber cuáles serán sus beneficios finales, qué habrá a su haber después de entregar su tiempo y energía en una acción. Pedir que los ciudadanos y ciudadanas sacrifiquen parte de su interés pri- 
vado en una causa compartida, parece, bajo la asunción del altruismo recíproco, poco realista.

Volvamos ahora sobre la cuestión del hiato que ha atravesado nuestra reflexión aquí. ¿Qué lugar tiene el ethos efectivo de la ciudadanía, frente a las expectativas de transformación social propias de los movimientos de la sociedad civil en la actualidad?

El marco teórico que hemos elegido para la comprensión de la cuestión, nos permite entender la naturaleza humana como una realidad compleja en lugar de una unidad monológica, como la que subyace a la idea del homo oeconomicus, es por ello que podemos afirmar que un proyecto político republicano, que enarbole los ideales, de justicia, igualdad, respeto por la diferencia y libertad, es un proyecto antropológicamente realista. Sin embargo esta misma complejidad nos revela los obstáculos que dicho proyecto ha de sortear. Se trata de ese ethos de la desconfianza y del free riding como única estrategia de supervivencia en una sociedad injusta, que ha adquirido carta de naturaleza en la nuestra y que es reivindicado por los sectores más nihilistas o que se sienten más desilusionados de la política. La frase "Si no lo hago yo, alguien más lo va a hacer”, refleja el cálculo racional que subyace a este tipo de actitudes. Afortunadamente hay mucho más en nuestro acervo evolutivo y cultural que puede permitirnos llevar a cabo un proyecto igualitario. Es preciso, no obstante, facilitar el ambiente tecnológico y no tecnológico que haga posible la emergencia y desarrollo de dichas motivaciones, y para esto necesitamos penetrar profundamente en la cotidianeidad de los ciudadanos y ciudadanas, así como también de quienes residen y cuyas vidas transcurren en nuestro país.

No sólo somos egoístas, sino muchas cosas más, algunas de ellas determinadas biológicamente. Hay disposiciones distintas que operan y coexisten en distintos procesos cognitivos y en nuestras motivaciones en la acción. Ningún diseño institucional que se precie de ser realista, así como ningún proyecto de transformación social puede ignorar la cuestión de cómo pueden alentarse las disposiciones cívicas y canalizar las egoístas para que produzcan una sociedad igualitaria. Siguiendo a Félix Ovejero:

"Las instituciones deben detectar el pecado sin desalentar la virtud, deben poder funcionar en previsión de bajas motivaciones públicas pero sin que ello las incapacite para absorber y alentar las disposiciones cívicas.”(Ovejero 2008: 34)

Hasta ahora hemos pensado nuestras instituciones políticas, sociales, culturales y económicas desde esa perspectiva "realista” que se regocija en las motivaciones planas del homo oeconomicus, planas en su monismo y planas en su aparente inmutabilidad. Esta suerte de etología política se exhibe cuando los sectores más conservadores se afirman en la imposibilidad de cambiar las estructuras de reparto del poder, en tanto insisten en la preeminencia del congreso para decidir cuestiones y la inviabilidad de que 
estas ajusten sus agendas a las presiones provenientes de la sociedad civil o del reparto de los beneficios, en tanto buscan naturalizar el lucro en la provisión de bienes públicos como la educación o asumen que sin este sería imposible satisfacer la demanda social de dichos bienes.

El hiato entre el deseo político de la sociedad civil y la desazón de lo social, solo puede salvarse con instituciones porosas y abiertas al cambio y a la crítica desde las bases, que son finalmente las que le proporcionan su legitimidad democrática, esa legitimidad democrática que hoy echamos en falta.

¿Qué lugar debería ocupar la academia en este proceso de transformación de la sociedad? La Universidad, como institución cultural está atravesada a su vez por las instituciones políticas, económicas y sociales, podemos decir que está también a merced de ellas. Y con todo, ha sido la cuna de un movimiento social que no solo ha cuestionado el lugar de la educación como bien público, sino la configuración misma de las estructuras sociales, sus repartos de poder político y económico. Ha reclamado para sí lo político en un romance ambiguo e intermitente con las viejas banderas de los partidos.

No se trata de una discusión que deba darse única y ni siquiera privilegiadamente en la academia, sino de una discusión que entre sus múltiples focos, encuentra la academia como uno más. Así como esta fue un lugar donde en los años 80 se discutieron los fundamentos del nuevo orden económico en que hoy habitamos, y se dio lugar a la interpretación hoy dominante en Chile de Adam Smith, que deja de lado la mitad de su obra y la posibilidad de una comprensión diferente de las relaciones entre ética y economía, de la mano de una antropología más compleja y más adecuada a nuestra propia experiencia de la vida entre los otros y las otras. Ahora es tal vez la hora de que la academia recupere esas interpretaciones que han sido sesgadas en el pasado, en favor de otras que nos permitan aportar nuevos elementos a los debates políticos actuales. Sobre la base de una antropología política diferente, los proyectos políticos aparecen bajo una nueva luz y un nuevo atractivo. Y es precisamente de hacer aparecer la transformación de la sociedad como algo atractivo y realizable, de lo que finalmente se trata.

Habría que rescatar entonces a ese Smith de la Teoría de los Sentimientos Morales, y releer desde ahí todo su proyecto. Siguiendo a Christian Marouby:

“Contrariamente a la versión empobrecida de las motivaciones humanas que implica una parodia antropológica, el homo sympatheticus de la teoría smithiana tiene toda la multidimensionalidad del ser socio-simbólico que el hombre es realmente en el mundo, tomado en la especularidad infinita de relaciones que posee con sus semejantes y en las múltiples redes de solidaridad sin las cuales no puede existir.” (Marouby 2005: 23-24) 
Pensar así una economía guiada por la mano invisible ya no parece conducir necesariamente a los resultados nefastos de una economía desregulada, que hasta ahora se han amparado en ella. La mano invisible es también el libre juego de la pluralidad de motivaciones humanas, de esas motivaciones que nos inclinan hacia los demás, pero que también nos repelen. Algo de esto lo dejaba ver Kant en su idea de la insociable sociabilidad. Los seres humanos somos seres infinitamente necesitados de los demás y es por ello que la solidaridad ha jugado un rol fundamental en nuestra evolución como especie y lo ha jugado en nuestro desarrollo como individuos. Un proyecto político que se afirme en ella no podría estar destinado al fracaso por ninguna razón natural, pero tampoco su éxito está inscrito en el genoma humano. Dada la multidimensionalidad de las motivaciones humanas, el papel de los arreglos institucionales que un proyecto republicano adopte para sí, es el de cultivar aquellas que refuerzan la solidaridad y la libertad y mantienen a raya la codicia y la violencia. Un proyecto republicano debe hacer que la alternativa de la cooperación se atractiva, a la vez que desincentivar la alternativa contraria. (De Francisco 2012) Nada de esto es antinatural ni inhumano ni un retroceso social, es más bien la expresión política de aquellos instintos sociales sin los cuales nuestra especie no habría podido florecer. 


\section{Notas}

${ }^{1}$ El debate en torno a la selección de grupo, que tuvo su momento álgido en los años 60 y 70 del pasado siglo y que fue abandonado luego, consagrando a la selección individual como única alternativa razonable, parece haber recobrado cierta fuerza en los últimos años, gracias a trabajos como el de D.S Wilson y E.O Wilson. (2008) y en menor medida el de Field (2001).

${ }^{2}$ Avner Grief (2006: 5), siguiendo la convención en el estudio económico de las instituciones, distingue entre los factores tecnológicos y los no-tecnológicos en una sociedad. Entre los primeros sitúa la localización geográfica, el conocimiento útil y el capital social, mientras que entre los factores no tecnológicos, señala las leyes, la forma de asegurar su cumplimiento y la distribución de los derechos de propiedad.

${ }^{3}$ Para una reflexión en torno al alcance de la teoría de juegos para la ética y la filosofía política, véase (Domènech 1989). 


\section{Bibliografía}

Axelrod, Robert M (1984), The evolution of cooperation. Basic Books, New York.

Darwin, Charles (1981), The Descent of Man and Selection in Relation to Sex. Princeton University Press, Princeton.

Ídem. (2008), On the Origin of Species,Oxford University Press. Oxford U.K

Dawkins, Richard (2006), The selfish gene, Oxford University Press. Oxford U.K; New York.

Francisco, A. de. (2012). La mirada republicana.Catarata, Madrid.

Domènech, Antoni (1989), De La Ética a La Política: De La Razón Erótica a La Razón Inerte. Critica, Barcelona.

Field, A. J. (2001). Altruistically inclined?_: the behavioral sciences, evolutionary theory, and the origins of reciprocity. Ann Arbor: University of Michigan Press, Michigan.

Gargarella, Roberto, José Luis Martí, and Félix Ovejero, eds. (2003), Nuevas Ideas Republicanas: Autobierno Y Libertad, Paidós, Barcelona.

Greif, Avner (2006), Institutions And The Path To The Modern Economy: Lessons from Medieval Trade, Cambridge University Press, Cambridge U.K

Marouby, Christian ( 2005), "Pour Une Économie De La Sympathie. Propos Sur La Double Anthropologie d'Adam Smith.” Finance \& Bien Commun 22 (2): 18. Observatoire de la finande, Ginebra.

Ovejero, Félix (2008), Incluso Un Pueblo De Demonios: Democracia, Liberalismo, Republicanismo, katz, Madrid.

Rancie_re, Jacques (2006), El Odio a La Democracia. Amorrortu Editores, Buenos Aires.

Rawls, John. (1979), Teoría De La Justicia. Fondo de Cultura Económica, México.

Ruse, Michael (2009), “Is Darwinian Metaethics Possible (And If It Is, Is It Well Taken)?” en Evolutionary Ethics and Contemporary Biology, Giovanni Boniolo y Gabriele De Anna eds. Cambridge University Press, Cambridge U.K

Trivers, Robert (1971), “The Evolution of Reciprocal Altruism.” Quarterly 
Review of Biology 46 (1): University of Chicago, Chicago.

Wilson, David Sloan, Wilson, Edward O., (2008) "Evolution for the Good of the Group.” American Scientist 96 September-October.

Recibido: 16.10 .12

Aceptado: 09.01.2013 